\title{
Physical Activity Levels by Occupational Category in Non-Metropolitan Australian Adults
}

\author{
Mitch J. Duncan, Hannah M. Badland, and William Kerry Mummery
}

\begin{abstract}
Background: The aim of this study was to examine the relationship between occupational category and 3 health-related behaviors: participation in leisure-time physical activity, active transport (AT) and occupational sitting in a sample of employed Australian adults. Methods: A random, cross-sectional sample of 592 adults aged 18 to 71 years completed a telephone survey in October/November 2006. Reported occupations were categorized as professional $(n=332,56.1 \%)$, white-collar $(n=181,30.6 \%)$, and blue-collar $(n=79,13.3 \%)$. Relationships between occupational category and AT, sufficient physical activity and occupational sitting were examined using logistic regression. Results: White-collar employees $(\mathrm{OR}=0.36,95 \%$ CI $0.14-0.95)$ were less likely to engage in AT and more likely to engage in occupational sitting $(\mathrm{OR}=3.10,95 \% \mathrm{CI} 1.63-5.92)$ when compared with blue-collar workers. Professionals ( $\mathrm{OR}=3.04,95 \% \mathrm{CI} 1.94-4.76)$ were also more likely to engage in occupational sitting compared with blue-collar workers. No relationship was observed between occupational category and engagement in sufficient physical activity. Conclusions: No association between occupational category and sufficient physical activity levels was observed, although white-collar and professionals were likely to engage in high levels of occupational sitting. Innovative and sustainable strategies are required to reduce occupational sitting to improve health.
\end{abstract}

Keywords: occupational category, active transport, barriers, sitting time

\section{Background}

Workplaces are unique settings to implement physical activity interventions as they provide access to large population groups, although evidence of sustained changes in physical activity is not strong. ${ }^{1-3} \mathrm{~A}$ recent review of workplace interventions identified increasing participation in active transport (AT), reducing sitting time, and increasing incidental activity as useful strategies to improve employee physical activity. ${ }^{1}$ Interventions to promote AT have demonstrated modest improvements in AT engagement. ${ }^{4-6}$ Due to the number of individuals required to travel to workplaces replicating these changes in AT could have considerable public health importance as AT is associated with increased physical

Duncan is with the Centre for Physical Activity Studies, Institute for Health and Social Science Research, CQUniversity, Rockhampton, Australia. Badland is with the Centre for Physical Activity and Nutrition Research, Auckland University of Technology, Auckland, New Zealand. Mummery was with the Centre for Physical Activity Studies, Institute for Health and Social Science Research, CQUniversity, Rockhampton, Australia at the time of writing. Mummery is now with the Faculty of Physical Education and Recreation, University of Alberta, Edmonton, Canada. activity levels, ${ }^{7,8}$ reduced the risk of several chronic health conditions, ${ }^{9-12}$ and reduced vehicle use and emissions. ${ }^{13}$ Interventions demonstrated improvements in AT when implemented in broad workplace groups, rather than being targeted at subpopulations employed in the workforce. ${ }^{4-6}$ The effectiveness of these approaches may be increased if targeted toward specific groups as some evidence indicates that travel mode selection varies across industrial sectors. ${ }^{14}$

Increasing incidental activity throughout the day reduces the volume of occupational sitting which is associated with reduced risk of excess weight and type 2 diabetes, independent of participation in leisure-time physical activity, and sociodemographics. ${ }^{15,16}$ Sedentary and physical activity behaviors have been examined independently, ${ }^{15,17-20}$ and several studies have examined multiple activity behaviors (leisure, occupational, household, commuting) by occupational sectors or categories in previous research..$^{21,22}$ These observations suggest that blue-collar workers or those in less skilled occupations participate in higher levels of occupational activity, report lower levels of leisure-time activity, and engage in less overall occupation related sedentary behaviors when compared with other occupational categories. . $^{15,17-19,21,23}$ Yet there are few studies that examine the relationships between specific subpopulations within the workforce such as different occupational categories and participation in multiple health related activity behaviors including sedentary activities, particularly within nonmetropolitan 
settings. Accordingly, the current study examines differences in AT participation, overall physical activity levels and occupational sitting time by occupational categories in sample of Australian adults residing in nonmetropolitan Queensland.

\section{Methods}

\section{Sampling}

The Central Queensland Social Survey (CQSS) is an annual omnibus survey conducted by the Population Research Laboratory, at CQUniversity in OctoberNovember 2006 (summer). The Central Queensland region is a nonmetropolitan area comprised of large regional cities and smaller regional centers and respondents were selected across all of these areas. Details of the CQSS sampling methodology are provided elsewhere. ${ }^{24}$ Briefly, English speaking adults living in Central Queensland, Australia, age 18 years and over were randomly selected from the electronic telephone white pages and invited to complete a computer assisted telephone interview (CATI) survey. Calls were made between 10:30 AM to 2:30 PM and 4:30 PM to 8:30 PM Monday to Sunday, and a 5-time callback system was implemented. Of the 1230 participants who completed interviews ( $41 \%$ response rate), $48.1 \%$ of the sample $(n=592)$ were eligible for the present analysis as they indicated they traveled to a worksite and their occupational category could be determined. The response rate of the current study is similar to that of other recently conducted CATI surveys. ${ }^{25-27}$ The age range of the entire sample and those eligible for the current analysis is 18 to 93 years and 18 to 71 years, respectively; the reduced age range of the eligible sample is broadly reflective of the current working practices of Australian adults. Informed consent was obtained before participating in the survey and the host institution ethics committee approved the study protocol. No data are available for those individuals who declined to participate in the survey.

\section{Demographics and Occupation Category Classifications}

Participants provided information on age, gender, years of education, height, weight, number of registered motor vehicles at the household and current occupation classification according to the Australian Standard Classification of Occupations. ${ }^{28}$ This classification has 9 categories as follows:

1. Managers and administrators

2. Professionals

3. Associate professionals

4. Tradespersons and related workers

5. Advanced clerical and service workers

6. Intermediate clerical, sales, and services workers

7. Intermediate, production, and transport workers
8. Elementary clerical sales and service workers

9. Laborers and related workers.

These 9 categories were reduced to 3 categories for analysis: professionals (managers and administrators, professionals and associate professionals); white-collar workers (elementary, intermediate, and advanced clerical, sales, and service workers); and blue-collar workers (tradespersons, intermediate production, and transport workers, laborers, and related workers). These categories have been used previously to examine activity patterns in occupational groups. ${ }^{15,18}$

\section{Travel Behaviors}

AT engagement was determined using the question: "In a usual week, how often would you walk or cycle for the majority of the commute distance from your home to or from your usual place of work?" If participants engaged in at least 1 trip by walking or cycling, they were considered to engage in AT. The self-reported length of participants' usual commute route was determined by asking: "In kilometers, how long is your usual journey to your usual place of work by all modes of transport?"24

\section{Physical Activity Engagement}

Physical activity engagement was assessed using the Active Australia Questionnaire. ${ }^{29}$ Participants reported the frequency and duration of physical activity in the previous week. The instrument required participants to recall the frequency and time spent in walking for transportation and recreation, moderate intensity and vigorous intensity-physical activity engagement separately, and has demonstrated appropriate test-retest reliability ${ }^{30}$ and validity. ${ }^{31}$ Physical activity level was classified according to standard Active Australia definitions. ${ }^{29}$ The sample was subsequently grouped into insufficiently and sufficiently active categories according to standardized definitions (insufficiently active $=<150$ minutes of physical activity per week irrespective of number of sessions reported; sufficiently active $=\geq 150$ minutes of physical activity per week accumulated in 5 or more sessions). ${ }^{32}$

\section{Occupational Sitting Time}

The total time spent sitting during working hours was determined for all respondents using the question "In hours and/or minutes, what do you estimate is the total time that you spend sitting during an average working day." 15 There are no data available on the psychometric properties of this question, however, it has previously been used to demonstrate associations between occupational sitting time and risk of overweight and obesity. ${ }^{15}$ Respondents were categorized as spending more or less than 5 hours per day in occupational sitting activities. This cut-point was selected as it represents the majority of time during a typical seven and a quarter-hour working day while still providing the opportunity to engage in ambulatory activities throughout the day. 


\section{Analysis}

Descriptive statistics were calculated and chi-square tests were used to examine demographic variables by occupational categories. Logistic regression models were used to examine the association between occupational categories and participation in AT, sufficient physical activity engagement, and occupational sitting time. Model 1 was adjusted for gender, age, years of education, BMI, usual travel distance, vehicle accessibility, and leisure-time physical activity. Model 2 was adjusted for gender, age, years of education, BMI, and AT. Model 3 was adjusted for gender, age, years of education, BMI, and leisure-time physical activity. All analyses were conducted using SPSS v15 (SPSS Inc., IL).

\section{Results}

Of the 592 eligible participants, 181 (30.6\%), 79 (13.3\%), and $332(56.1 \%)$ were classified as being employed in blue-collar, white-collar, and professional occupations, respectively. A higher proportion of males were classified as blue-collar workers compared with females $(P$ $\leq$.001) (Table 1). Overall participation rates in AT and

Table 1 Sample Description by Occupational Category

\begin{tabular}{|c|c|c|c|c|c|}
\hline & \multicolumn{5}{|c|}{ Occupational category } \\
\hline & $\begin{array}{c}\text { Overall sample } \\
N(\%)\end{array}$ & $\begin{array}{c}\text { Blue-collar } \\
\mathrm{N}(\%) \\
\end{array}$ & $\begin{array}{c}\text { White-collar } \\
\mathbf{N}(\%)\end{array}$ & $\begin{array}{c}\text { Professional } \\
\mathbf{N}(\%)\end{array}$ & $\boldsymbol{P}$ \\
\hline Gender & & & & & $<0.001$ \\
\hline Male & $338(57.1)$ & $146(80.7)$ & $18(22.8)$ & $174(52.4)$ & \\
\hline Female & $254(42.9)$ & $35(19.3)$ & $61(77.2)$ & $158(47.6)$ & \\
\hline Age (years) & & & & & 0.018 \\
\hline $18-34$ & $125(21.2)$ & $47(26.1)$ & $21(26.6)$ & $57(17.2)$ & \\
\hline $35-44$ & $187(31.6)$ & $51(28.3)$ & $17(21.5)$ & $119(35.8)$ & \\
\hline $45-54$ & $188(31.8)$ & $54(30.0)$ & $33(41.8)$ & $101(30.4)$ & \\
\hline $55+$ & $91(15.4)$ & $28(15.6)$ & $8(10.1)$ & $55(16.6)$ & \\
\hline Education (years) & & & & & $<0.001$ \\
\hline $0-10$ & $147(25.0)$ & $62(34.4)$ & $26(33.3)$ & $59(17.9)$ & \\
\hline $11-12$ & $137(23.3)$ & $50(27.8)$ & $29(37.2)$ & $58(17.6)$ & \\
\hline $13-14$ & $86(14.6)$ & $34(18.9)$ & $11(14.1)$ & $41(12.4)$ & \\
\hline$\geq 15$ & $218(37.1)$ & $34(18.9)$ & $12(15.4)$ & $172(52.1)$ & \\
\hline BMI & & & & & 0.511 \\
\hline Healthy weight & $203(34.6)$ & $64(36.0)$ & $31(39.7)$ & $108(33.1)$ & \\
\hline Overweight/obese & $379(65.1)$ & $114(64.0)$ & $47(60.3)$ & $218(66.9)$ & \\
\hline AT participation & & & & & 0.456 \\
\hline No AT & $508(85.8)$ & $152(84.0)$ & $71(89.9)$ & $285(85.8)$ & \\
\hline$\geq 1$ AT journey/week & $84(14.2)$ & $29(16.0)$ & $8(10.1)$ & $47(14.2)$ & \\
\hline Physical activity participation & & & & & 0.629 \\
\hline Insufficient & $307(52.0)$ & $98(54.4)$ & $38(48.1)$ & $171(51.7)$ & \\
\hline Sufficient & $283(48.0)$ & $82(45.6)$ & $41(51.9)$ & $160(48.3)$ & \\
\hline Occupational sitting time/day & & & & & $<0.001$ \\
\hline$<5$ hours & $351(59.7)$ & $134(74.0)$ & $48(62.3)$ & $169(51.2)$ & \\
\hline$\geq 5$ hours & $237(40.3)$ & $47(26.0)$ & $29(37.7)$ & $161(48.8)$ & \\
\hline Work travel distance/day & & & & & 0.001 \\
\hline$\leq 5$ kilometers & $246(42.6)$ & $57(32.0)$ & $44(56.4)$ & $145(45.0)$ & \\
\hline$\geq 5$ kilometers & $332(57.4)$ & $121(68.0)$ & $34(43.6)$ & $177(55.0)$ & \\
\hline Vehicle accessibility & & & & & 0.464 \\
\hline$\leq 1$ vehicle & $116(19.7)$ & $41(22.8)$ & $14(17.9)$ & $61(18.5)$ & \\
\hline$\geq 2$ vehicles & $472(80.3)$ & $139(77.2)$ & $64(82.1)$ & $269(81.5)$ & \\
\hline
\end{tabular}


sufficient physical activity levels were $14.2 \%$ and $48.0 \%$ respectively. A lower proportion of blue-collar workers $(26.0 \%)$ reported more than 5 hours of occupational sitting time compared with white-collar (37.7\%) and professionals (48.8\%). A higher proportion of white-collar workers reported usual travel distances less than $5 \mathrm{~km}$ $(\mathrm{km})$ compared with blue-collar workers and professionals $(P \leq .001)$.

Compared with blue-collar workers, white-collar workers were less likely to participate in AT $(\mathrm{OR}=0.36$, 95\% CI 0.14-0.95). Professionals were also less likely to participate in AT compared with blue-collar workers, although this association did not reach statistical significance $(\mathrm{OR}=0.68,95 \%$ CI $0.36-1.27)$ (Table 2). White-collar workers $(\mathrm{OR}=1.38,95 \% \mathrm{CI} 0.76-2.52)$ and professionals $(\mathrm{OR}=1.19,95 \% \mathrm{CI} 0.78-1.81)$ were more likely to report sufficient levels of physical activity compared with blue collar workers although these associations did not achieve statistical significance. Compared with those who reported no AT engagement, those who reported AT participation were more likely to be sufficiently active (OR $=4.25,95 \%$ CI $2.46-7.36)$. White-collar (OR $=3.10,95 \%$ CI $1.63-5.92)$ and professional workers (OR $=3.04,95 \%$ CI 1.94-4.76) were more likely to sit for the majority of their working day compared with blue-collar workers.

\section{Discussion}

The current study observed that compared with bluecollar workers, white-collar workers were less likely to engage in AT and more likely to report higher levels of occupational sitting time and shorter travel distances.
Low levels of AT engagement and high levels of occupational sitting time are related to various adverse health outcomes placing this occupation group at increased risk. ${ }^{10,12,33}$ It should be noted that the same patterns of associations were observed in professionals also; however the association with AT engagement was not statistically significant. Despite the small sample size of the current study the pattern of findings are interesting as they relate to multiple behaviors assessed within the same population group which may be useful for the development of future interventions.

Relationships between occupational sitting time and occupational category are very likely the outcome of inherent differences in job requirements; in general, bluecollar workers are required to spend more time engaged in ambulatory activities rather than sitting. This is evidenced in other studies demonstrating blue-collar workers are more active during work hours ${ }^{18,19}$ and spend less time sitting ${ }^{20}$ compared with other occupational groups. Irrespective of these job requirements recent research has shown that it is important to reduce sitting behavior in both leisure and occupational settings. ${ }^{34}$ Targeting incidental activities to increase movement throughout the day may be a potential strategy, ${ }^{1}$ although other intervention strategies that target historically seated activities have been suggested ${ }^{35}$ and may be useful in workplace settings. However, there is the need to understand other ways to reduce sitting time across all occupation groups. Although the current study observed that participation in AT was associated with participation in sufficient physical activity, it did not observe that occupational groups which were more likely to engage in AT were also more likely to be active. However, there is potential that increasing AT

Table 2 Associations Between Socio-Demographic Categories and Likelihood to Engage in AT, Sufficient Physical Activity, and Occupational Sitting

\begin{tabular}{|c|c|c|c|c|c|c|}
\hline \multirow[b]{3}{*}{ Variable } & \multicolumn{2}{|c|}{ Model 1} & \multicolumn{2}{|c|}{ Model 2} & \multicolumn{2}{|c|}{ Model 3} \\
\hline & \multicolumn{2}{|c|}{ Occupational AT $^{\mathrm{a}}$} & \multicolumn{2}{|c|}{ Sufficient PA ${ }^{b}$} & \multicolumn{2}{|c|}{ Occupational sitting time } \\
\hline & OR & $95 \% \mathrm{Cl}$ & OR & $95 \% \mathrm{Cl}$ & OR & $95 \% \mathrm{Cl}$ \\
\hline \multicolumn{7}{|c|}{ Occupation category } \\
\hline Blue-collar & & Reference & & Reference & & Reference \\
\hline White-collar & 0.36 & $0.14-0.95$ & 1.38 & $0.76-2.52$ & 3.10 & $1.63-5.92$ \\
\hline Professional & 0.68 & $0.36-1.27$ & 1.19 & $0.78-1.81$ & 3.04 & $1.94-4.76$ \\
\hline \multicolumn{7}{|c|}{ Physical activity participation } \\
\hline Insufficient & & Reference & - & - & & Reference \\
\hline Sufficient & 4.65 & $2.60-8.29$ & - & - & 1.03 & $0.72-1.48$ \\
\hline \multicolumn{7}{|l|}{ AT participation } \\
\hline 0 AT trips & - & - & & Reference & - & - \\
\hline$\geq 1$ AT trips & - & - & 4.25 & $2.46-7.36$ & - & - \\
\hline
\end{tabular}

${ }^{a} \mathrm{~N}=563$. Adjusted for gender, age, years of education, BMI, usual travel distance, vehicle accessibility, and physical activity participation.

${ }^{b} \mathrm{~N}=583$. Adjusted for gender, age, years of education, BMI, and AT.

${ }^{c} \mathrm{~N}=580$. Adjusted for gender, age, years of education, BMI, and physical activity participation. 
engagement would alter overall levels of sitting and activity, and if sustained long-term, could generate significant improvements in health status. To date, little is known about physical activity compensation with regard to AT engagement, although it is known that many obstacles to the behavior remain including environmental and societal barriers to the successful implementation of AT interventions in large population groups.

The overall level of AT participation in the current sample was low, although comparable to other Australian data ${ }^{36}$ and higher than that observed in New Zealand adults. ${ }^{26}$ Similar to previous studies the current study observed that participation in participation in AT was associated with engaging in sufficient physical activity. ${ }^{7,37}$ This provides some confidence that the current observation did not occur by chance in the presence of the wide confidence intervals surrounding the estimate. Given the low level of AT to work and the health, environmental, and economic benefits associated with AT, ongoing efforts to sustain and promote the behavior should be continued. The current sample displayed a high level of access to motor vehicles where approximately $80 \%$ had access to 2 or more vehicles in their home. Although adjusted for in the analysis, it may be that other factors such as needing to transport other passengers or trip chaining purposes make AT to work unfeasible for some individuals. Despite these points, $42 \%$ of the current sample reported their travel distance was less than 5 kilometers. Even withstanding the limitations of self-reported travel distances ${ }^{38}$ and trip chaining barriers, our findings suggest that many adults in nonmetropolitan areas could be expected to travel to work using AT modes, and that distance for many would not be a significant barrier to work-related AT.

Other studies observed that blue collar workers have lower levels of leisure-time physical activity engagement compared with other employee groups in US and Dutch populations. ${ }^{18,22}$ In the current study a lack of association was observed between physical activity engagement and occupational category and is contrast to these previous findings. ${ }^{17,22}$ These contrasting observations are nonetheless interesting and should be examined further in the Australian context. The lack of association occurred in the presence of differences in AT engagement by occupational categories, which is relevant given the current study and others demonstrate participation in AT to be associated with increased overall activity. ${ }^{7,37}$ Examination of the relationship between physical activity level and occupational category with the addition of AT engagement as an interaction term may have provided insight on this lack of association. However, small cell sizes prohibited such interactions to be examined. It is also possible that some compensatory effect is present in other domains of activity for those individuals engaging in AT, however we are unable to explore this issue in the current study as it did not assess all domains of activity. Other limitations of the current study include the relatively small sample size which reduced the potential for interactions between occupation categories and other variables of interest to be examined. All modes of transport during the journey to work were not examined, as only the mode used for the majority of the journey was reported. This may have resulted in a slight under-representation of the true prevalence of AT as trip chaining and public transport journeys may have been omitted. With regard to trip chaining, future research should examine how factors such as the need to travel to several places in a journey or transport others to diverse destinations may influence AT engagement and perceptions. Data were collected during summer; this may have resulted in a downward bias of AT prevalence because of the warm summer climate in the study region, although this bias is not expected to be large. Forthcoming research in this area should also examine broader travel behaviors, such as requiring a car for work purposes, public transport access and potential physical activity compensation.

\section{Conclusions}

The current study observed that white-collar workers and professionals were more likely to report high levels of occupational sitting and white-collar workers were less likely to engage in AT compared with blue-collar workers. There was no association between occupational category and participation in sufficient'physical activity. Interventions to increase AT and reduce occupational sitting are likely to increase the overall activity of workers and produce favorable changes in health outcomes. Travel distance did not appear to be a significant barrier to AT in this sample and may indicate the utility of AT interventions in nonmetropolitan areas.

\section{Acknowledgments}

This research was supported by the Population Research Grant Scheme 2006, Centre for Social Science Research, Central Queensland University. HB is supported by a New Zealand National Heart Foundation Research Fellowship.

\section{References}

1. Marshall AL. Challenges and opportunities for promoting physical activity in the workplace. $J$ Sci Med Sport. 2004;7:60-66.

2. Proper KI, Staal BJ, Hildebrandt VH; van der Beek AJ, van Mechelen W. Effectiveness of physical activity programs at worksites with respect to work-related outcomes. Scand $J$ Work Environ Health. 2002;28:75-84.

3. Dishman RK, Oldenburg B, O'Neal H, Shephard RJ. Worksite physical activity interventions. Am J Prev Med. 1998;15:344-361.

4. Mutrie N, Carney C, Blamey A, Crawford F, Aitchison T, Whitelaw A. "Walk in to work out": a randomised controlled trial of a self help intervention to promote active commuting. I Epidemiol Community Health. 2002;56:407-412.

5. Oja P, Vuori I, Paronen O. Daily walking and cycling to work: their utility as health-enhancing physical activity. Patient Educ Couns. 1998;33:S87-S94. 
6. Wen LM, Orr N, Bindon J, Rissel C. Promoting active transport in a workplace setting: evaluation of a pilot study in Australia. Health Promot Int. 2005;20:123-133.

7. Cole R, Leslie E, Bauman A, Donald M, Owen N. Sociodemographic variations in walking for transport and for recreation or exercise among adult Australians. $J$ Phys Act Health. 2006;3:164-178.

8. Berrigan D, Troiano RP, McNeel T, Disogra C, Ballard-Barbash R. Active transportation increases adherence to activity recommendations. Am J Prev Med. 2006;31:210-216.

9. Hou L, Ji BT, Blair A, Dai Q, Gao YT, Chow WH. Commuting physical activity and risk of colon cancer in Shanghai, China. Am J Epidemiol. 2004;160:860-867.

10. Hu G, Qiao Q, Silventoinen K, et al. Occupational, commuting, and leisure-time physical activity in relation to risk for Type 2 diabetes in middle-aged Finnish men and women. Diabetologia. 2003;46:322-329.

11. Hayashi T, Tsumura K, Suematsu C, Okada K, Fujii S, Endo G. Walking to work and the risk for hypertension in men: The Osaka Health Survey. Ann Intern Med. 1999;131:21-26.

12. Hamer M, Chida Y. Active commuting and cardiovascular risk: a meta-analytic review. Prev Med. 2008;46(1):9-13.

13. Higgins PAT. Exercise-based transportation reduces oil dependence, carbon emissions and obesity. Environ Conserv. 2005;32:197-202.

14. Sirigapore Department of Statistics. Census of population 2000: geographic distribution and travel. Singapore: Singapore Department of Statistics; 2001.

15. Mummery WK, Schofield GM, Steele R, Eakin EG, Brown WJ. Occupational sitting time and overweight and obesity in australian workers. Am J Prev Med. 2005;29:91-97.

16. Hu FB, Li TY, Colditz GA, Willett WC, Manson JE. Television watching and other sedentary behaviors in relation to risk of obesity and Type 2 diabetes mellitus in women. JAMA. 2003;289:1785-1791.

17. Caban-Martinez AJ, Lee DJ, Fleming LE, et al. Leisuretime physical activity levels of the US workforce. Prev Med. 2007;44:432-436.

18. Steele R, Mummery K. Occupational physical activity across occupational categories. J Sci Med Sport. 2003;6:398-407.

19. Schofield G, Badlands H, Oliver M. Objectively-measured physical activity in New Zealand workers. J Sci Med Sport. 2005;8:143-151.

20. Jans MP, Proper KI, Hildebrandt VH. Sedentary behavior in dutch workers: differences between occupations and business sectors. Am J Prev Med. 2007;33:450-454.

21. Salmon J, Owen N, Bauman A, Schmitz MK, Booth M. Leisure-time, occupational, and household physical activity among professional, skilled, and less-skilled workers and homemakers. Prev Med. 2000;30:191-199.

22. Proper KI, Hildebrandt VH. Physical activity among Dutch workers-differences between occupations. Prev Med. 2006;43:42-45.
23. Miller R, Brown W. Steps and sitting in a working population. Int J Behav Med. 2004;11:219-224.

24. Badland HM, Duncan MJ, Mummery WK. Travel perceptions, behaviors, and environment by degree of urbanization. Prev Med. 2008;47(3):265-269.

25. Ainsworth BE, Wilcox S, Thompson WW, Richter DL, Henderson KA. Personal, social, and physical environmental correlates of physical activity in African-American women in South Carolina. Am J Prev Med. 2003;25:2329.

26. Badland HM, Schofield G. Health associations with transport-related physical activity and motorized travel to destinations. International Journal of Sustainable Transport. 2008;2:77-90.

27. Caperchione CM, Duncan MJ, Mummery K, Steele R, Schofield G. Mediating relationship between body mass index and the direct measures of the theory of planned behaviour on physical activity intention. Psychol Health Med. 2008;13:168-179.

28. Australian Bureau of Statistics. Australian standard classification of occupations (ASCO). 2nd ed. Canberra: Australian Government Publishing Service; 1997.

29. Brown W, Bauman A, Chey T, Trost S, Mummery K. Comparison of surveys used to measure physical activity. Aust N Z J Public Health. 2004;28:128-134.

30. Brown WJ, Bauman A, Trost S, Mummery WK, Owen N. Test-retest reliability of four physical activity measures used in population surveys. J Sci Med Sport. 2004;7:205215.

31. Timperio A, Salmon J, Bull F, Rosenburg M. Validation of adult physical activity questions for use in australia population surveys. Canberra: Department of Health and Ageing. Unpublished report; 2002.

32. Australian Institute of Health and Welfare. The active Australia survey: A guide and manual for implementation, analysis and reporting. Canberra: AIHW; 2003.

33. Healy GN, Dunstan DW, Salmon J, et al. Breaks in sedentary time: beneficial associations with metabolic risk. Diabetes Care. 2008;31:661-666.

34. Hamilton MT, Hamilton DG, Zderic TW. Role of low energy expenditure and sitting in obesity, metabolic syndrome, Type 2 diabetes, and cardiovascular disease. Diabetes. 2007;56:2655-2667.

35. Levine JA, Miller JM. The energy expenditure of using a "Walk-and-Work" Desk for office workers with obesity. Br J Sports Med. 2007;41:558-561.

36. Burke M, Brown AL. Distances people walk for transport. Road and Transport Research. 2007;16:16-29.

37. Cerin E, Leslie E, Toit L, Owen N, Frank LD. Destinations that matter: associations with walking for transport. Health Place. 2007;13:713-724.

38. Stopher P, FitzGerald C, Xu M. Assessing the accuracy of the Sydney household travel survey with GPS. Transportation. 2007;34(6):723-741. 
Copyright of Journal of Physical Activity \& Health is the property of Human Kinetics Publishers, Inc. and its content may not be copied or emailed to multiple sites or posted to a listserv without the copyright holder's express written permission. However, users may print, download, or email articles for individual use. 